\title{
A case of craniofacial dysmorphism, congenital heart defects, coccygeal skin folds, generalized skeletal alterations, and hemihypertrophy with linear skin hypopigmentation: A new syndrome?
}

Received: September 5, 1997 / Accepted: October 3, 1997

\begin{abstract}
The case of a Japanese girl with a unique combination of congenital malformations is reported. The malformations include craniofacial dysmorphism, congenital heart defects, coccygeal skin folds, generalized skeletal alterations, and hemihypertrophy with linear skin hypopigmentation that indicated somatic mosaicism of a mutated gene or a submicroscopic chromosomal aberration. The phenotype in our patient overlapped significantly with, but was not completely consistent with, that of ter Haar syndrome, a recently elucidated malformation syndrome with an autosomal recessive trait. The present patient may have represented a previously undescribed malformation syndrome, or an atypical manifestation of ter Haar syndrome due to somatic mosaicism.
\end{abstract}

Key words ter Haar syndrome - Caudal appendage . Hemihypertrophy $\cdot$ Linear skin hypopigmentation $\cdot$ Somatic mosaicism

\section{Introduction}

Despite expanding knowledge of clinical dysmorphology, many malformations in children remain undefined. Therefore, further clinical investigation is mandatory to establish clinical entities and their long-term prognosis. We report here the case of a child with a hitherto unknown combination of malformations. The key to diagnosis in the present patient was the recognition of hemihypertrophy with skin pigmentary alterations and caudal skin folds, because this occurs rarely in congenital malformation syndromes.

G. Nishimura $(\bowtie)$

Department of Radiology, Dokkyo University School of Medicine, 880 Kitakobayashi, Mibu, Shimotsuga-gun, Tochigi 321-02, Japan

Tel. +81-282-87-2171; Fax +81-282-86-4940

e-mail: gen-n@dokkyomed.ac.jp

T. Nagai

Department of Pediatrics, Dokkyo University Koshigaya Hospital,

Saitama, Japan

\section{Clinical report}

The patient was a Japanese girl who was the third child of unrelated parents. The father was healthy, but it was noted that the mother was of short stature $(147 \mathrm{~cm})$. The maternal grandmother $(137 \mathrm{~cm})$ and maternal aunt $(150 \mathrm{~cm})$ were also short. The patient's elder sister and younger brother were healthy. The patient was vaginally delivered at 41 weeks' gestation after an unremarkable pregnancy. Birth length was $50.0 \mathrm{~cm}(+0.6 \mathrm{SD})$, weight $3006 \mathrm{~g}(-0.2 \mathrm{SD})$, and head circumference $32.5 \mathrm{~cm}(-0.5 \mathrm{SD})$. No perinatal asphyxia was evident. At age 1 month, she attracted medical attention due to feeding difficulties. Cardiac examination disclosed a ventricular septal defect, an atrial septal defect, and patent ductus arteriosus, for which total corrective surgery was performed at age 3 months. Despite successful cardiac surgery, she failed to thrive: height was $65.0 \mathrm{~cm}$ $(-2.5 \mathrm{SD})$ and weight $6200 \mathrm{~g}(-2.6 \mathrm{SD})$ at age 10 months; height $70.0 \mathrm{~cm}(-2.4 \mathrm{SD})$ and weight $7500 \mathrm{~g}(-1.8 \mathrm{SD})$ at age 14 months.

Developmental milestones were normal: she kept her head steady at age 3 months, sat alone at age 7 months, stood without support at age 12 months, and spoke comprehensive words at age 14 months. At age 2 years and 10 months, she was referred for evaluation of short stature and facial dysmorphism. Height was $84.0 \mathrm{~cm}(-2.0 \mathrm{SD})$ and weight $10.3 \mathrm{~kg}(-1.8 \mathrm{SD})$. The craniofacial dysmorphism included a broad forehead with mild frontal bossing, a boxlike skull with flat occiput, proptosis with prominent eyes, significant hypertelorism, long eyelashes, a short nose with anteverted nostrils, a long philtrum, low-set and prominent ears, and micrognathia with a high arched palate (Fig. 1a). Coccygeal skin folds were evident (Fig. 1b). The limbs were asymmetrical: the left extremities were larger than the right. The length of the left hand measured $10.6 \mathrm{~cm}(-0.5 \mathrm{SD})$, whereas that of the right was $9.9 \mathrm{~cm}(-2.0 \mathrm{SD})$. Linear hypopigmented lesions were seen on the legs. Mild laxity was evident in all limb joints. Ophthalmologic examination did not reveal marked abnormalities. Routine laboratory examinations were not noteworthy. Chromosome analysis 
Fig. 1a A photograph of patient (permission given by a guardian for publication); b A photograph of the buttocks in patient. Note facial abnormalities and coccygeal skin folds
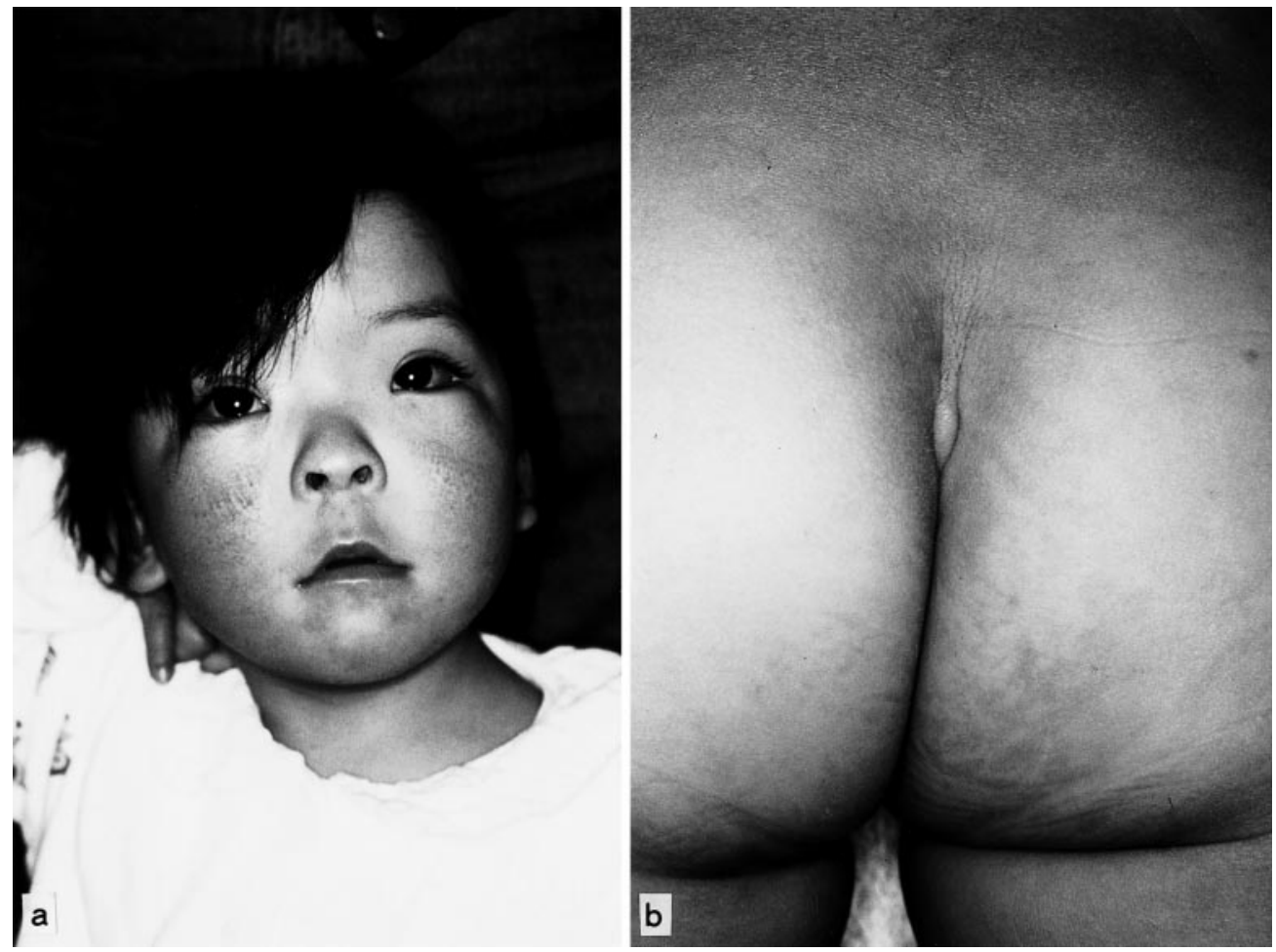

of lymphocytes showed a normal karyotype. Skin biopsy was not approved by the parents.

Radiological examination revealed not only craniofacial abnormalities, including a box-like calvarial deformity with flat occiput and short skull base, hypoplastic facial bones, and recession of the mandible, but also generalized abnormalities in the axial and appendicular skeleton, including twisted ribs, tall vertebral bodies with increased interpediculate distance of the lumbar spine, narrow iliac wings, vertical ischia, and coxa valga (Fig. 2a-d). The skeletal age of the left hand was more advanced than that of the right (Fig. 2e). The length of the left short tubular bones ranged from -1.0 to $-0.2 \mathrm{SD}$ of the mean, whereas that of the right short tubular bones was from $-2.8 \mathrm{SD}$ to $-1.3 \mathrm{SD}$ (some epiphyseal ossification centers of the right short tubular bones were not ossified).

\section{Discussion}

The major features in the present patient included craniofacial dysmorphism, caudal skin folds, limb asymmetry with linear skin hypopigmentation, and generalized skeletal alterations (Table 1). The limb asymmetry was considered to be due to hemihypertrophy on clinical and radiological grounds. The skeletal alterations were individually minor, but the constellation was considered to benefit the syndromic identification. Short stature was another cardinal feature in our patient, but it may have been related to dominant familial short stature in the maternal pedigree. Among these major features, hemihypertrophy with skin pigmentary alterations and caudal skin folds were relevant to the diagnosis because of the rare occurrence of these features in congenital malformation syndromes; accordingly, the differential diagnosis is addressed from this point of view.

The combination of hemihypertrophy with skin pigmentary changes occurs in several hamartomatous and malformation syndromes, such as neurofibromatosis, McCune-Albright syndrome, Proteus syndrome, and hypomelanosis of Ito, all of which apparently differ from the disorder of our patient. Woods et al. (1994) reported six patients with asymmetry and skin pigmentary anomalies in chromosome mosaicism. The clinical manifestations of these patients are also distinguishable from those of our patient. It should be emphasized that hemihypertrophy or asymmetry in the four entities cited is related to somatic mosaicism of a mutated gene or a chromosomal aberration (Weinstein et al. 1991; Cohen 1993; Woods et al. 1994), which may also contribute to the phenotypic manifestation in our patient.

Caudal skin folds occur in metatropic dysplasia (Kozlowski et al. 1988), Teebi-Shaltout syndrome (Teebi and Shaltout 1989), Golabi-Rosen syndrome (Golabi and Rosen 1984), BBB-like syndrome with brachydactyly (Rippberger and Aase 1976), and ter Haar syndrome (ter Haar et al. 1982). Most of these entities are readily distinguishable from the present disorder; thus we address here only ter Haar syndrome.

As shown in Table 1, phenotypic overlap apparently exists between the disorder of our patient and ter Haar syndrome, which was formerly coined autosomal recessive 

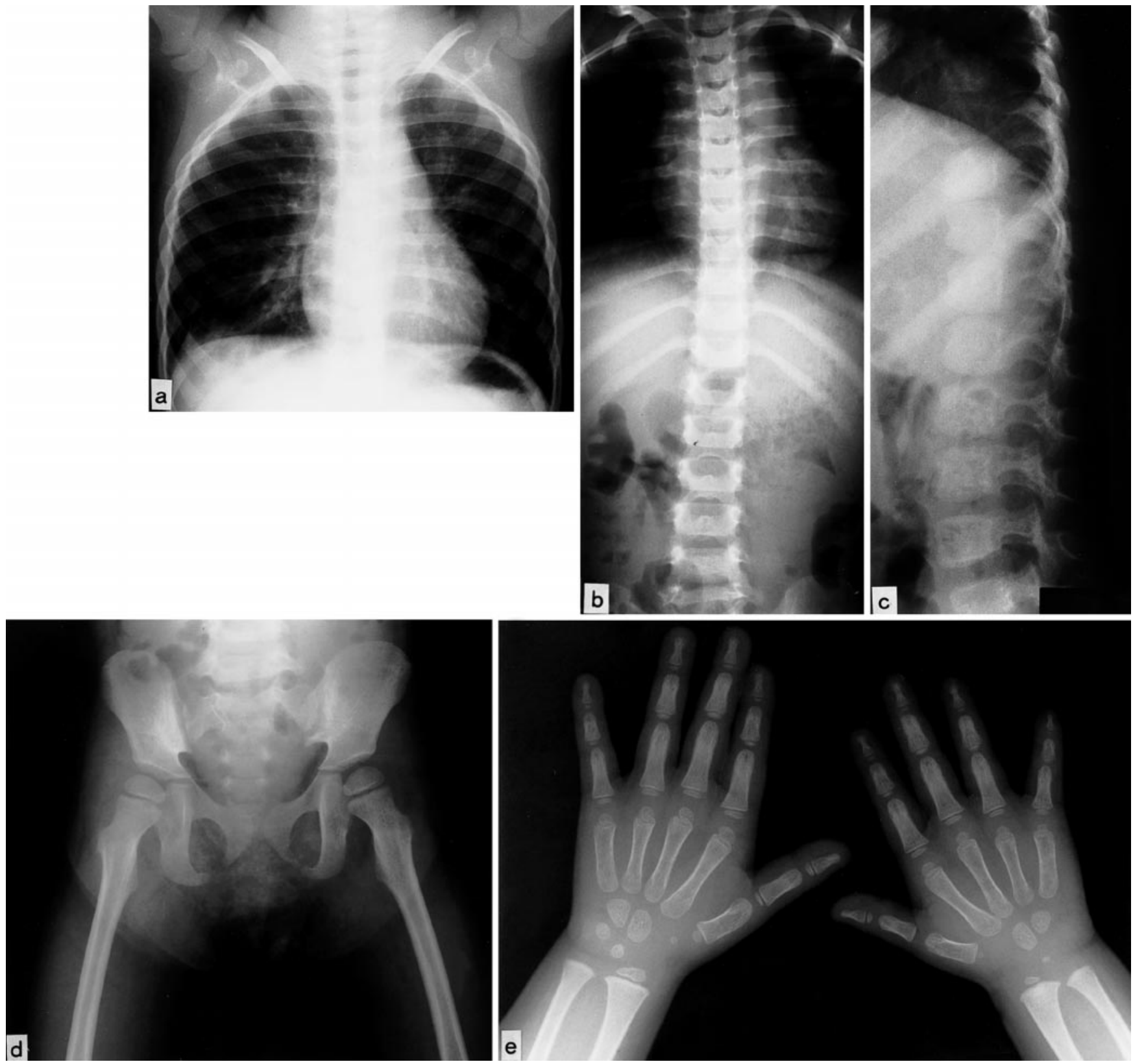

Fig. 2a-e Radiographs of patient. Note twisted ribs (a), tall vertebral bodies with increased interpediculate distance of the lumbar spine (b), narrow iliac wings (c), vertical ischia (d), and coxa valga

Melnick-Needles syndrome and whose features are based on five patients (ter Haar et al. 1982; Billette de Villemeur et al. 1992; Hamel et al. 1995). Nevertheless, the constellation of each craniofacial abnormality, which is generally more conspicuous in ter Haar syndrome than in the present patient, gives rise to different facial gestalts. The cardiac defects in ter Haar syndrome are similarly more severe than those of the present patient. Megalocornea with congenital glaucoma, camptodactyly, and clubfeet found in ter Haar syndrome were not present in our patient, whereas the hemihypertrophy with linear skin hypopigmentation in our patient is not a feature in ter Haar syndrome. (e). Left hemihypertrophy with more advanced epiphyseal ossification is evident

However, the somatic mosaicism that may exist in our patient would preclude the full manifestation of the disorder and create the atypical and milder phenotype; therefore, it can not be completely excluded that the present patient represents an atypical manifestation of ter Haar syndrome. It is of interest that two patients with ter Haar syndrome showed overgrowth at birth: $55 \mathrm{~cm}$ birth length and $4500 \mathrm{~g}$ birth weight in one, and $56 \mathrm{~cm}$ birth length and $4510 \mathrm{~g}$ birth weight in the other (ter Haar et al. 1982). In fact, the somatic mosaicism of a mutated gene responsible for overgrowth syndrome should give rise to hemihypertrophy.

In summary, the syndromic constellation reported here 
Table 1 Clinical and radiologic features in ter Haar syndrome and our patient

\begin{tabular}{|c|c|c|c|}
\hline & \multirow[t]{2}{*}{ Our patient } & \multicolumn{2}{|l|}{ ter Haar syndrome } \\
\hline & & ter Haar and Hamel & Billette de Villemeur \\
\hline Sex & $\mathrm{F}$ & $\mathrm{M} / \mathrm{F}: 3 / 1$ & $\mathrm{~F}$ \\
\hline Birth weight (g) & 3006 & $3180-4510$ & $?$ \\
\hline \multicolumn{4}{|l|}{ Craniofacial } \\
\hline Frontal bossing & + & $4 / 4$ & + \\
\hline Brachycephaly & a box-like skull & $3 / 3$ & $?$ \\
\hline Flat occiput & + & $4 / 4$ & $?$ \\
\hline Wide fontanels & $?$ & $4 / 4$ & + \\
\hline Hypertelorism & + & $4 / 4$ & + \\
\hline Long eyelashes & + & $3 / 3$ & + \\
\hline Short nose & + & $4 / 4$ & + \\
\hline Low-set ears & + & $3 / 3$ & + \\
\hline Micrognathia & + & $3 / 4$ & + \\
\hline \multicolumn{4}{|l|}{ Eyes } \\
\hline Prominent eyes & + & $4 / 4$ & + \\
\hline Megalocornea & - & $2 / 2$ & + \\
\hline Glaucoma & - & $2 / 2$ & + \\
\hline \multicolumn{4}{|l|}{ Musculoskeletal } \\
\hline Kyphoscoliosis & - & $2 / 4$ & $?$ \\
\hline Coccygeal skin folds & + & $4 / 4$ & $?$ \\
\hline Clubfeet & - & $3 / 4$ & + \\
\hline Joint laxity & + & $?$ & + \\
\hline Hypotonia & - & $2 / 2$ & $?$ \\
\hline Radiologic & & & $?$ \\
\hline Sclerotic skull base & - & $1 / 4$ & \\
\hline Spondylar dysplasia & + & $3 / 4$ & ? \\
\hline Flared or narrow ilia & + & $3 / 4$ & $?$ \\
\hline Vertical ischia & + & $3 / 4$ & $?$ \\
\hline Coxa valga & + & $1 / 2$ & $?$ \\
\hline Cortical irregularity & + (ribs) & $4 / 4$ & $?$ \\
\hline Hypoplastic phalanges & - & $4 / 4$ & ? \\
\hline Heart & $\mathrm{VSD}, \mathrm{ASD}, \mathrm{PDA}$ & DORV:2; VSD:1; MVP:1 & VSD \\
\hline \multicolumn{4}{|l|}{ Development } \\
\hline Motor retardation & - & $3 / 3$ & + \\
\hline Others & asymmetry; skin lesion & & \\
\hline Inheritance & sporadic & AR & possible AR \\
\hline
\end{tabular}

ASD, atrial septal defect; VSD, ventricular septal defect; DORV, double outlet of the right ventricle; MVP, mitral valve prolapse; AR, autosomal recessive; +, present; -, absent; ? absent or not determined.

did not fit any hitherto known congenital malformation syndromes, but suggested somatic mosaicism of a mutated gene or a submicroscopic chromosomal aberration as an underlying etiology, with manifestations overlapping in part with those of ter Haar syndrome. Therefore, it remains speculative whether the present patient may represent an atypical manifestation of ter Haar syndrome related to somatic mosaicism. Further case documentation is required to elucidate this issue.

\section{References}

Billette de Villemeur T, Bijaoui G, Beauvais P, Richardet JM (1992) Bowen syndrome: congenital glaucoma, flexion contracture of fingers and facial dysmorphism without peroxisomal abnormalities. Eur J Pediatr 151:146-147

Cohen MM Jr (1993) Proteus syndrome: Clinical evidence for somatic mosaicism and selective review. Am J Med Genet 47:645-652
Golabi M, Rosen L (1984) A new X-linked mental retardation-overgrowth syndrome. Am J Med Genet 17:345-358

Hamel BCJ, Draaisma JMT, Pinckers AJLG, Boetes C, Hoppe RLE, Ropers H-H, Brunner HG (1995) Autosomal recessive MelnickNeedles syndrome or ter Haar syndrome? Report of a patient and reappraisal of an earlier report. Am J Med Genet 56:312-316

Kozlowski K, Campbell J, Anderson B, Erken EHW, Jequier S, Nelson M, Sliman N, Sprague P, Tamaela LA (1988) Metatropic dysplasia and its variant (analysis of 14 cases). Australas Radiol 32:325337

Rippberger CW, Aase JM (1976) Case report 42. Syndr Ident 4: $16-19$

Teebi AS, Shaltout AA (1989) Craniofacial anomalies, abnormal hair, camptodactyly, and caudal appendage. Am J Med Genet 33:58-60

ter Haar B, Hamel B, Hendriks J, de Jager J (1982) Melnick-Needles syndrome: indication for an autosomal recessive form. Am J Med Genet 13:469-477

Weinstein LS, Shenker A, Gejman PV, Merino MJ, Friedman E, Spiegel AM (1991) Activation mutations of the stimulatory G protein in the McCune-Albright syndrome. N Engl J Med 325:16881695

Woods CG, Bankier A, Curry J, Sheffield LJ, Slaney SF, Smith K, Voullaire L, Wellesley D (1994) Asymmetry and skin pigmentary anomalies in chromosome mosaicism. J Med Genet 31:694-701 